\title{
Application of P-A Fractal Model in the River Network of the Landslides Area
}

\author{
Zhiwang WANG ${ }^{*}$ \\ Changjiang River Scientific Research Institute \\ Wuhan, China. \\ e-mail:wzwhbwh@126.com
}

\author{
Fangfang ZHOU, Hao CAO \\ Research Center on Water Engineering Safety and Disaster \\ Prevention of the Ministry of Water Resources, \\ Wuhan, China. \\ e-mail:zhouff5@126.com, cinsulator625@126.com
}

\begin{abstract}
Abstract-This paper applies $P$-A model to study the fractal characteristics of 17 sub-watersheds in the study area from Badong county to Zigui county in TGP reservoir region. The results indicate that the small watersheds have obvious fractal characteristics and that the fractal of water system in the study area has obvious spatial differentiation. The $D_{A P}$ fractal dimension is usually higher in the places where the erosion of the landscape is more serious and there is more landslides relatively. The relationship between the fractal dimension of topography and landform and the development of landslide is closely related to the erosion of the river. The results show that the P-A fractal model provides powerful tools for quantitative description of the river network and the relationship between the river network and the landslides.
\end{abstract}

Keywords- P-A fractal model; river network; landslide)

\section{INTRODUCTION}

Since Mandelbrot proposed the fractal concept in 1977, many fractal models have been proposed to quantitatively describe the irregularities of geometrical objects and modes. Among them, the P-A model is used to describe the irregular geometrical features of similar objects. The P-A model was first proposed by Mandelbrot (1982), the so-called "island lake model", which relates the perimeter and area of an irregularly deformed geometry with self-similarity to measure irregularly complex sections, including computational sections fractal dimension. Cheng (1995) proposed a new general expression for the P-A model. The new P-A model is not only applicable to the regular section set but also to the fractal set. In this paper, GIS-based P-A general model is used to quantitatively describe the irregularities of water system.

\section{STUdy AREA AND DATA SETS}

Landslide is be prone to occur and to cause natural hazards in the Three Gorges reservoir region, where there are varied topographies, complicated geological structures, and heavy annual rainfall. The landslide hazards often destroyed houses, road and farmlands. So it is thus important to study the landslide in the area to reduce the landslide hazards, and to ensure the reservoir safety. The study area is located in Hubei province from Zigui to Badong counties. There are many landslides, which are usually located in the section with "hard" rock and "soft" rock jointly and along the bank of the river. The landslides often caused serious damage to the area (Wu et al. 2001). The main data for this study is the 1:50,000 scale digitized geological map and DEM, from which the river network and the sub-basins were obtained.

\section{A. Maintaining the Integrity of the Specifications}

The template is used to format your paper and style the text. All margins, column widths, line spaces, and text fonts are prescribed; please do not alter them. You may note peculiarities. For example, the head margin in this template measures proportionately more than is customary. This measurement and others are deliberate, using specifications that anticipate your paper as one part of the entire proceedings, and not as an independent document. Please do not revise any of the current designations.

\section{THE P-A METHOD}

At present, there are many fractal models that describe the irregularities of the geometric objects and mode shapes. Among them, the P-A model is a very effective method to describe the irregular geometric features of the objects with similar geometric characteristics and has been widely used (Cheng, 2004; Zhang et al., 2001). This paper uses the P-A model to quantitatively describe the irregularity of regional landslide distribution.

The P-A general model (Cheng, 1995) has the following expression:

$$
P(>A) \propto A^{\frac{1}{2} D_{A P}}
$$

\section{RESULTS AND DISCUSSION}

The distribution maps of the second and third level catchment basins respectively based on the DEM data. The perimeter-area model (P-A model) was used to calculate and analyze the of the second and third level sub-basins in 17 small watersheds in the study area. $\log \mathrm{P} \sim \log \mathrm{A} \log$ arithmic relationship curves (Fig. 2, Fig. 3) show that there is a clear linear relationship between the logarithm of the catchment area and the logarithm of the perimeter. That is, there is a clear power law relationship between the area and the perimeter. The correlation coefficient $\mathrm{R}^{2}$ is mostly greater than 0.9 , indicating that the linear correlation is good, which shows that the watersheds and water systems in these small watersheds have obvious fractal characteristics. It can be seen from the $\mathrm{D}_{\mathrm{AP}}$ fractal dimension distribution map (Fig. 4, 
Fig. 5) of the catchment basins in class 2 and 3 of the study area that there is a significant correlation between the distribution of $\mathrm{D}_{\mathrm{AP}}$ fractal dimension values and the landslides spatial distribution. The $\mathrm{D}_{\mathrm{AP}}$ fractal dimension is usually higher in the places where the erosion of the landscape is more serious and there is more landslides relatively.

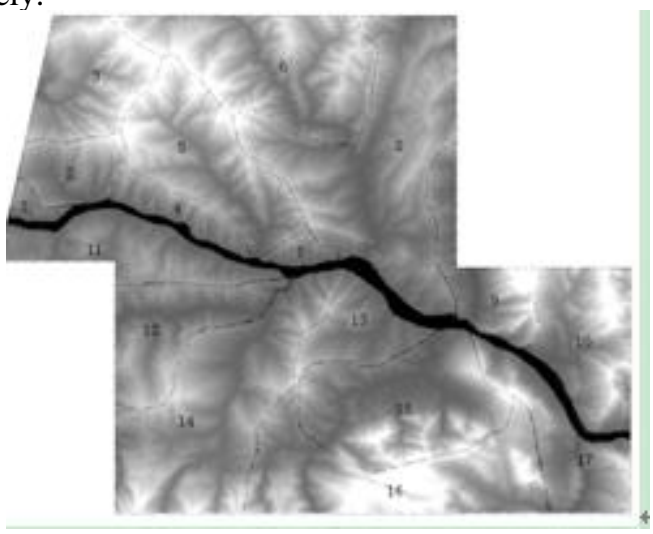

Figure 1. DEM and the sub-basins of the study area.
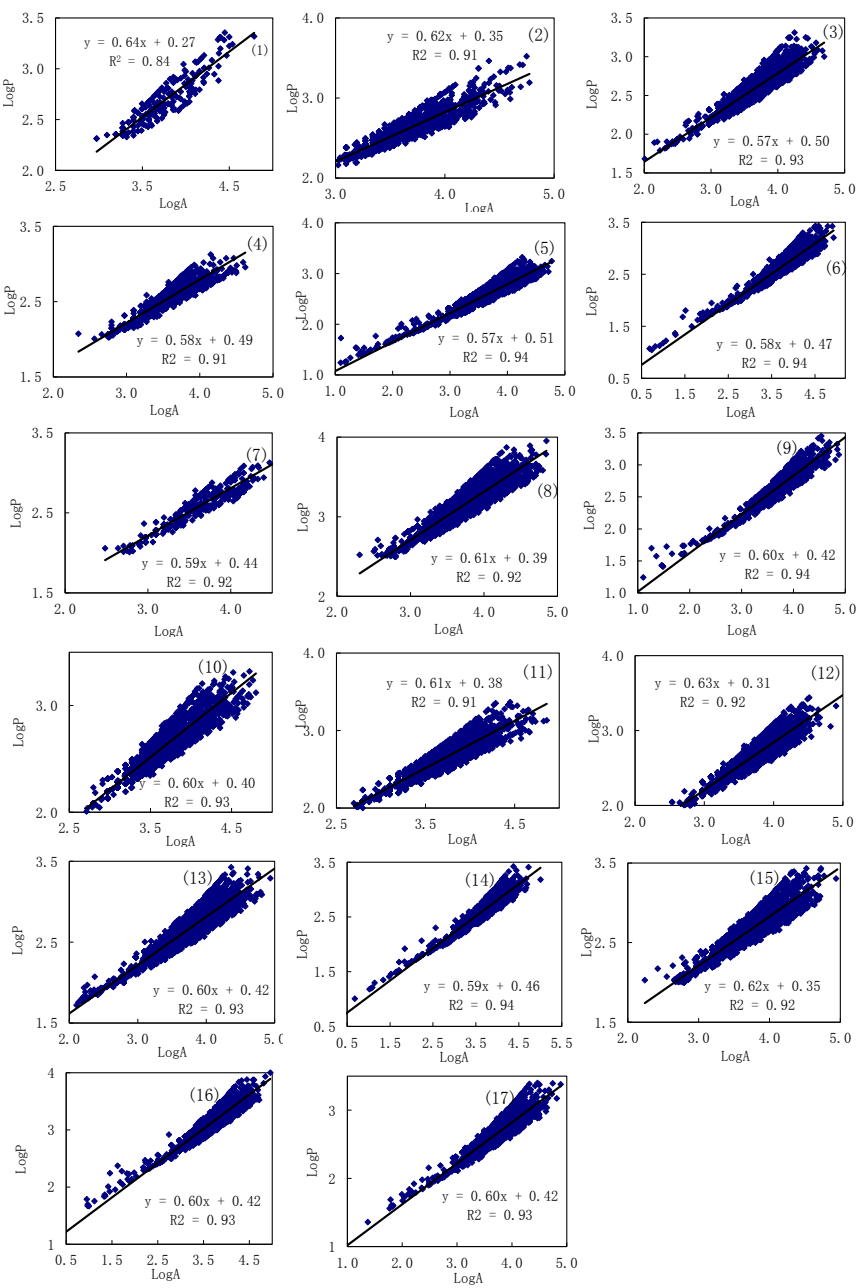

Figure 2. The fractral dimensions plot of the river network in the second level sub-basins
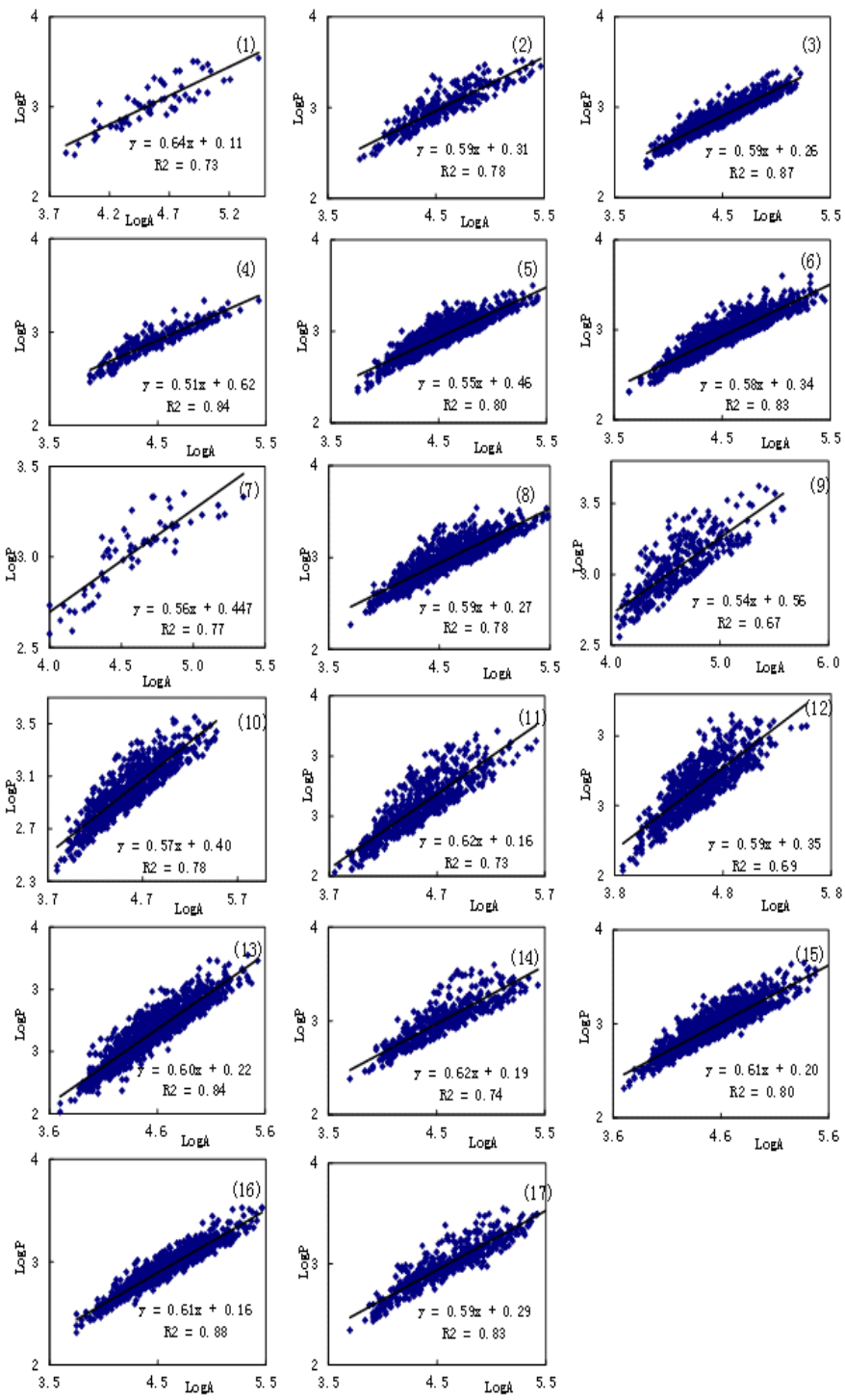

Figure 3. The fractral dimensions plot of the river network in the third level sub-basins.

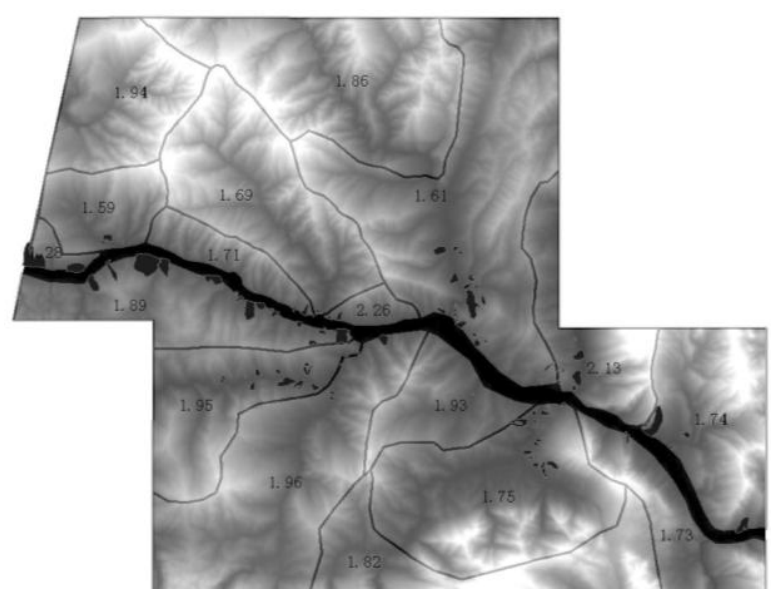

Figure 4. The fractral dimensions of the river network in the second level sub-basins of the study area. 


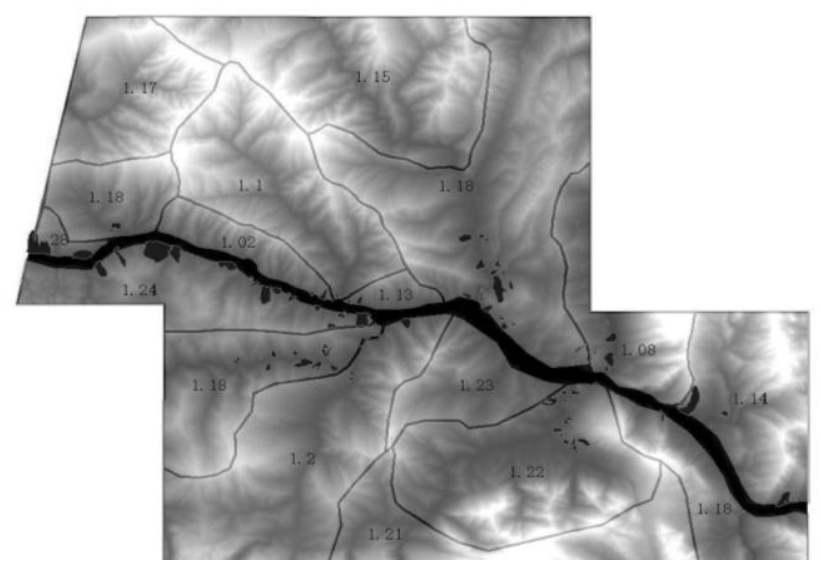

Figure 5. The fractral dimensions of the river network in the third level sub-basins of the study area.

\section{CONCLUSIONS}

P-A model can be used to characterize the fractal characteristics of the river network in the landslides area. The data obtained from the study area shows power-law distributions of the logarithm of the catchment area and the logarithm of the perimeter, and thus reveals some fractal or self-similarity properties. The fractal model provides powerful tools for quantitative description of the river network and the relationship between the river network and the landslides

\section{ACKNOWLEDGMENT}

This research was financially supported by the National Natural Science Foundation of China (No.51379023), and the Public Welfare Research Project sponsored by Ministry of Water Resources of China (201501033-3).

\section{REFERENCES}

[1] Wu, S., Shi, L., Wang, R., Tan, C., Hu, D., Mei, Y., Xu, R: Engineering Geology Vol. 59(2001), p. 51

[2] Mandelbrot B. B.: J. Fluid Mechanics, 1974,62 331

[3] Falconer K, 1990 Fractal Geometry. Wiley, New York, pp 288

[4] Cheng Q 2004 Math. Geology,36 345 